\title{
EVALUATION OF LOW-FREQUENCY VOLTAGE DIVIDERS, USING THE STEP RESPONSE
}

\author{
Daniel Slomovitz, Pablo Bergalli, Jorge Fernández Daher \\ UTE LABORATORIO, Paraguay 2385, Montevideo, Uruguay \\ FAX: 598-2-9242004, E.MAIL: labute@chasque.apc.org
}

\begin{abstract}
A method to characterize the behavior of lowfrequency voltage dividers, based on the step response, is presented. Amplitude errors and phase displacements can be evaluated, in an absolute way, without any auxiliary standard divider.
\end{abstract}

\section{Description of the method}

Resistive dividers, for audio frequencies, are commonly used in the input circuits of voltmeters, wattmeters and similar instruments. The step response method consists of the application of a very fast step voltage at the input of the divider, while measuring the output voltage. This technique is not commonly used for these kind of dividers, although is very usual for high voltage dividers used with impulse waveforms [1]. The dividers are linear components, so their operational response is

$$
H(p)=\frac{1+a_{1} p+a_{2} p^{2}+a_{3} p^{3}+\ldots}{1+b_{1} p+b_{2} p^{2}+b_{3} p^{3}+\ldots}
$$

Under sinusoidal excitation, the complex variable $p$ becomes j $\omega$. At low frequencies the higher order terms, can be neglected. Then

$$
H(j \omega)=\frac{1+j \omega a_{1}-\omega^{2} a_{2}}{1+j \omega b_{1}-\omega^{2} b_{2}}
$$

The phase displacement $\delta$, considering that $\omega a_{1}$ and $\omega b_{1}$ are much smaller than one and neglecting the second order terms, is

$$
\delta=-\omega\left(b_{1}-a_{1}\right)
$$

On the other hand, the difference $b_{1}-a_{1}$ can be computed from the normalized step response $g(t)$. In [1], it is shown that this difference has the same value than the parameter $T$, defined as

$$
\mathrm{T}=\int_{0}^{\infty}[1-\mathrm{g}(\mathrm{t})] \mathrm{dt}
$$

From (3) and (4)

$$
\delta=-\omega \mathrm{T}
$$

On the other hand, the amplitude error $\varepsilon$ (in per unit) has the value [1]

$$
\varepsilon=\omega^{2}\left(a_{1}^{2}-b_{1}^{2}-2 a_{2}+2 b_{2}\right) / 2
$$

Also in this case, $\varepsilon$ is related to the step response, through the parameter Ts, defined as

$$
T s^{2}=2 \int_{0}^{\infty} t(1-g(t)) d t-T^{2}
$$

by the relation

So

$$
T s^{2}=b_{1}{ }^{2}-a_{1}{ }^{2}+2\left(a_{2}-b_{2}\right)^{2}
$$

$$
\varepsilon=-\mathrm{Ts}^{2} \omega^{2} / 2
$$

Parameters $\mathrm{T}$ and Ts were proposed, as others, for the evaluation of high voltage impulse dividers. $T$ is commonly used, but Ts is not. Ts has not been accepted because its evaluation is very sensitive to noise and small variations in the steady state zone [2]. This zone is defined from $t_{0}$ (when the transient ends) to the end of the step response. The present standards, for impulse measurements, propose to use other parameters for evaluating those dividers. However, for sinusoidal waveforms, Ts is essential for evaluating the amplitude error.

To solve this problem, these authors propose to substitute the steady state zone $\left(t>t_{0}\right)$ of the measured response $g_{m}(t)$, by the function $g_{o}(t)$, calculated as

$$
g_{o}(t)=\frac{1}{\left(t-t_{o}\right)} \int_{t_{0}}^{t} g_{m}(\tau) d \tau
$$

this function makes a smoothing on the steady state zone, reducing the influence of the noise.

For computing $\mathrm{T}$ and $\mathrm{Ts}$, the program described in [3] was used. It was compared against other programs, 
that took part of an international comparison. Ts was not included in the comparison for the mentioned reason. To study its sensitiveness, $t_{0}$ was varied $10 \%$. For all responses used in the comparison, the variation of Ts was lower than 2 ns. This shows the high stability of the proposed method.

\section{Experimental example}

As an application example, the performance of a $270: 1$ divider $(500 \mathrm{~V}, 50 \mathrm{~Hz}$ to $10 \mathrm{kHz}, 270 \mathrm{k} \Omega$ input resistance) is discussed. It has a coaxial construction. For reducing the effect of stray capacitances, a partial cylindrical shield is used [4]. The step response of this divider, without the compensating shield, has the following parameters: $T=-33 \mathrm{~ns}, \mathrm{Ts}=48 \mathrm{j}$ ns. So, the phase displacement is $2000 \mu \mathrm{rad}$ at $10 \mathrm{kHz}$, and $10 \mu \mathrm{rad}$ at $50 \mathrm{~Hz}$. The amplitude error is $5 \mathrm{ppm}$ at $10 \mathrm{kHz}$. At 50 $\mathrm{Hz}$, it can be neglected.

Figure 1 shows the step response, with the best adjustment of the shield length, in order to reduce the phase displacement. The values of the response parameters are: $\mathrm{T}=-2 \mathrm{~ns}, \mathrm{Ts}=41 \mathrm{~ns}$. This means a phase displacement of $130 \mu \mathrm{rad}$ at $10 \mathrm{kHz}$, and smaller than 1 $\mu \mathrm{rad}$ at $50 \mathrm{~Hz}$. The amplitude error remains practically the same. At $50 \mathrm{~Hz}$, both errors can be neglected.

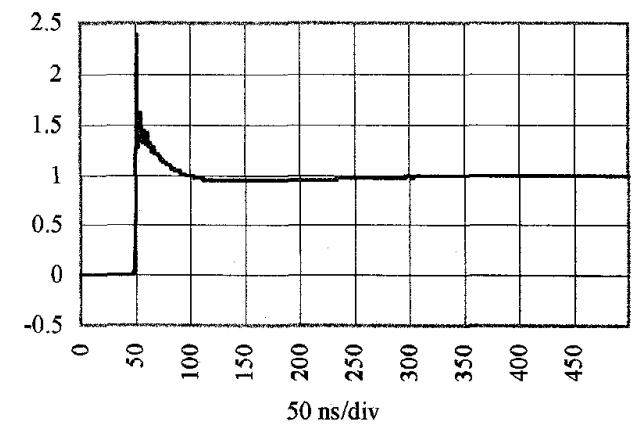

Figure 1

\section{Uncertainty of the method}

The proposed method is affected by the limited bandwidth of the digitizer, and the no ideal waveform of the step generator. The generator used is a very small one, with $3 \mathrm{~mm}$ of diameter and $20 \mathrm{~mm}$ of length [5]. The response of the set generator-digitizer was evaluated, connecting the generator directly to the digitizer $(\mathrm{BW}=300 \mathrm{MHz})$. The proposed parameters were calculated for this set $\left(\mathrm{T}_{\mathrm{g}}\right.$ and $\left.\mathrm{Ts}_{\mathrm{g}}\right)$. It is easy to see that the total-response parameters of the divider, including the response of the generator-digitizer $\left(T_{t}\right.$ and $\left.T s_{t}\right)$, is

$$
\begin{aligned}
& T_{t}=T+T_{g} \\
& T s_{t}^{2}=T s^{2}+T s_{g}^{2}
\end{aligned}
$$

The differences between the actual parameters of the divider ( $\mathrm{T}$ and $\mathrm{Ts}^{2}$ ) and the total measured parameters, is $\mathrm{T}_{\mathrm{g}}$ and $\mathrm{Ts}_{\mathrm{g}}{ }^{2}$. These values can be used as an estimation of the uncertainties of the method. For the experimental example shown, $\mathrm{T}_{\mathrm{g}}=0.4 \mathrm{~ns}$ and $\mathrm{Ts}_{\mathrm{g}}=1 \mathrm{~ns}$. This leads to an uncertainty of $25 \mu \mathrm{rad}$, in phase displacement at $10 \mathrm{kHz}$, and $0.1 \mu \mathrm{rad}$ at $50 \mathrm{~Hz}$. The amplitude uncertainty can be neglected, for all the range.

Other source of uncertainty, comes from the amplitude error of the digitizer. It depends, mainly, on the number of bits of the $\mathrm{AD}$ converter. For evaluating this error source, a boundary zone must be defined around the measured response. Moving different parts of the response between those limits, a worse case can be easily calculated. For a 10 bits converter, this uncertainty source generally can be neglected.

The proposed method can be applied to single resistors and current shunts, using an auxiliary resistor for constructing the divider. The resistor under test is one of the arms of the divider, and the auxiliary resistor, the other. In this case, an external reference standard is needed, but this method has the advantage that it makes possible to select the most convenient value for the auxiliary resistor, decreasing the influence of stray capacitances and inductances.

\section{References}

[1] N. Hyltén-Cavallius, High Voltage Laboratory Planning, Basel, HAEFELY, Ch.9, pp. 186-216, 1988.

[2] J. Rungis, K. Schon, "The evaluation of impulse divider response parameters," IEEE Trans. Pow. Del., Vol 3, No 1, pp. 88-95, Jan 1988.

[3] W. Mandl, L. Trigo, "Study on the stepresponse-parameters in impulse dividers," Dissertation submitted to Fac. de Ingeniería, Univ. Rep., Montevideo, Uruguay, Apr. 1997.

[4] F. Hermach, E. Williams, "Thermal voltage converters for accurate voltage measurements to 30 megacycles per second," AIEE Trans., pt. 1, vol. 79, pp. 200-206, Jul. 1960.

[5] J. Fernández, D. Slomovitz, "Development of a fast step generator for testing impulse dividers," ELECTROTECNICA, Vol. 81, pp. 233-240, Nov. 1995. 